\title{
Prescription Opioid Duration, Dose, and Increased Risk of Depression in 3 Large Patient Populations
}

\author{
Jeffrey F. Scherrer, $P b D^{1-3}$ \\ Joanne Salas, MPH ${ }^{1,2}$ \\ Laurel A. Copeland, PhD ${ }^{4-6}$ \\ Eileen M. Stock, $P b D^{4,5}$ \\ Brian K. Abmedani, $\mathrm{PbD}^{7}$ \\ Mark D. Sullivan, $M D^{8}$ \\ Thomas Burroughs, $\mathrm{PbD}^{3}$ \\ F. David Schneider, MD, MSPH ${ }^{1}$ \\ Katbleen K. Bucbolz, PbD ${ }^{9}$ \\ Patrick J. Lustman, $P b D^{9,10}$ \\ 'Department of Family and Community \\ Medicine, Saint Louis University School of \\ Medicine, St. Louis, Missouri \\ ${ }^{2}$ Harry S. Truman Veterans Administration \\ Medical Center, Columbia, Missouri \\ ${ }^{3}$ Saint Louis University Center for Out- \\ comes Research, St. Louis, Missouri \\ ${ }^{4}$ Center for Applied Health Research, Baylor \\ Scott \& White Health, and Central Texas \\ Veterans Health Care System, Temple, Texas \\ ${ }^{5}$ Texas A\&M Health Science Center, Bryan, \\ Texas \\ ${ }^{6}$ University of Texas Health Science Cen- \\ ter, San Antonio, Texas \\ ${ }^{7}$ Henry Ford Health System, Center \\ for Health Policy and Health Services \\ Research, Detroit, Michigan \\ ${ }^{8}$ Department of Psychiatry and Behavioral \\ Health, University of Washington School \\ of Medicine, Seattle, Washington \\ ${ }^{9}$ Department of Psychiatry, Washington \\ University School of Medicine, St. Louis, \\ Missouri \\ ${ }^{10}$ The Bell Street Clinic, VA St. Louis \\ Health Care System - John Cochran Divi- \\ sion, St. Louis, Missouri

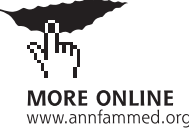 \\ Conflicts of interest: authors report none.
}

\section{CORRESPONDING AUTHOR}

Jeffrey F. Scherrer, PhD

Family and Community Medicine

Saint Louis University School of Medicine 1402 N Grand Blvd

St. Louis, MO 63104

scherrjf@slu.edu

\begin{abstract}
PURPOSE Recent results suggests the risk of a new onset of depression increases with longer duration of opioid analgesic use. It is unclear whether new-onset depression related to opioid analgesic use is a function of the dose prescribed or the duration of use or both.
\end{abstract}

METHODS Using a retrospective cohort design, we collected patient data from 2000 to 2012 from the Veterans Health Administration (VHA), and from 2003 to 2012 from both Baylor Scott $\&$ White Health (BSWH) and the Henry Ford Health System (HFHS). Patients (70,997 VHA patients, 13,777 BSWH patients, and 22,981 HFHS patients) were new opioid users, aged 18 to 80 years, without a diagnosis of depression at baseline. Opioid analgesic use duration was defined as 1 to 30, 31 to 90, and more than 90 days, and morphine equivalent dose (MED) was defined as 1 to $50 \mathrm{mg} / \mathrm{d}$, 51 to $100 \mathrm{mg} / \mathrm{d}$, and greater than $100 \mathrm{mg} / \mathrm{d}$ of analgesic. Pain and other potential confounders were controlled for by inverse probability of treatment-weighted propensity scores.

RESULTS New-onset depression after opioid analgesic use occurred in 12\% of the VHA sample, $9 \%$ of the BSWH sample, and $11 \%$ of the HFHS sample. Compared with 1- to 30-day users, new-onset depression increased in those with longer opioid analgesic use. Risk of new-onset depression with 31 to 90 days of opioid analgesic use ranged from hazard ratio $[\mathrm{HR}]=1.18(95 \% \mathrm{Cl}, 1.10-1.25)$ in VHA to $\mathrm{HR}=1.33(95 \% \mathrm{Cl}, 1.16-1.52)$ in HFHS; in opioid analgesic use of more than 90 days, it ranged from $\mathrm{HR}=1.35(95 \% \mathrm{Cl}, 1.26-1.44)$ in VHA to $\mathrm{HR}=2.05(95 \% \mathrm{Cl}, 1.75-2.40)$ in HFHS. Dose was not significantly associated with a new onset of depression.

CONCLUSIONS Opioid-related new onset of depression is associated with longer duration of use but not dose. Patients and practitioners should be aware that opioid analgesic use of longer than 30 days imposes risk of new-onset depression. Opioid analgesic use, not just pain, should be considered a potential source when patients report depressed mood.

Ann Fam Med 2016;14:54-62. doi: 10.1370/afm.1885.

\section{INTRODUCTION}

$\square$ epression co-occurs with chronic noncancer pain ${ }^{1,2}$ and is known to be associated with opioid use. Patients with chronic noncancer pain and depression are more likely than those without depression to receive opioids, ${ }_{1}^{3}$ have a longer duration of use, ${ }^{4,5}$ take them at higher morphine equivalent doses (MEDs), ${ }^{6}$ and misuse and or abuse opioids. ${ }^{7,8}$ A review of psychopathology in pain ${ }^{9}$ suggests the opioid epidemic in the United States reflects underdetected and undertreated mental illness in patients with chronic pain.

Every year more than 200 million prescriptions for opioids are written in the United States. ${ }^{10}$ Known consequences of this opioid epidemic include abuse and accidental overdose. ${ }^{11-13} \mathrm{~A}$ less understood adverse outcome and emerging line of inquiry is the association between opioid use and risk of depression. In a study of nearly 50,000 Veterans Health Administration (VHA) patients, opioid analgesic use of longer than 180 
days, compared with 1 to 90 days, was associated with significantly greater risk (hazard ratio $[\mathrm{HR}]=1.51 ; 95 \%$ CI, 1.31-1.74) of a new diagnosis for depression..$^{14}$ In a prospective study of chronic pain patients, those who increased their MED to more than $50 \mathrm{mg} / \mathrm{d}$, compared with nonusers, had a 2.6 times greater probability of depression with time. ${ }^{15}$ These results remained after rigorous control for confounding.

Depression may be associated with opioid resistance $^{16}$ and with opioid misuse. ${ }^{17-19}$ The large population of patients receiving opioid therapy may experience a parallel, yet unrecognized, increase in depression. Firmly establishing that greater duration, dose, or both of opioid analgesic use are associated with a new onset of depression, and in diverse patient populations, can inform pain management and public health incentives. A fuller understanding of opioid-related depression is relevant to primary care in light of the increased provision of pain management in this setting. ${ }^{20}$

Our prior studies of the link between opioid analgesic use and depression have several limitations, ${ }_{,}^{14,15}$ including unknown generalizability to other US health care populations, and uncertainty as to whether duration and dose are both associated with depression. In addition, our previous study of VHA patients relied on diagnosis of painful conditions without patientreported pain scores and was conducted using a cohort designed for studies of incident heart disease. ${ }^{21}$

In this study, we expand our previous research ${ }^{14,15}$ to determine (1) whether longer duration of opioid analgesic use is associated with new-onset depression

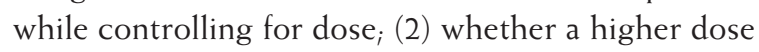
is associated with new-onset depression after adjusting for duration; (3) whether opioid analgesic use remains associated with new-onset depression after controlling for pain scores in VHA patient data ${ }_{i}$ and (4) and whether results generalize to 2 independent health care populations.

\section{METHODS}

Electronic medical record data were obtained from 3 separate health care systems: Veterans Health Administration (VHA), Baylor Scott \& White Health (BSWH), and the Henry Ford Health System (HFHS). The latter 2 systems used data from the HMO Research Network Virtual Data Warehouse. ${ }^{22}$ Data included International Classification of Diseases, 9th Revision, Clinical Modification (ICD-9-CM) diagnosis codes; prescription records, laboratory results, and demographic information.

\section{Cohort Eligibility}

Samples were restricted to those aged 18 to 80 years at baseline and excluded those with a diagnosis of cancer or human immunodeficiency virus infection. Patients must have had at least 1 visit in each of the 2 washout years before the start of follow-up period during which cases of depression and opioid use were removed. The 2-year washout has been applied previously as a conservative time frame to remove patients with common conditions. ${ }^{21,23}$ Patients must have had at least 1 visit after the follow-up period started. Patients who initiated opioid analgesic use after the onset of depression were excluded because they did not provide information regarding a new onset of depression. The end of the follow-up period was a new onset of depression or last known visit in the follow-up period. These criteria set up the temporal relationship so that incident opioid use occurred in patients without current depression and preceded any new-onset depression. The follow-up period was 2002 to 2012 in the VHA, and 2005 to 2012 in BSWH and HFHS. Measures

\section{Duration and Dose of Incident Period of Opioid Analgesic Use \\ Opioids included codeine, fentanyl, hydrocodone,} hydromorphone, levorphanol, meperidine, oxycodone, oxymorphone, morphine, and pentazocine. Patients were considered continuous users if no gap of more than 30 days occurred between the end of one prescription and the start of another. Duration was computed by summing the days' supply variable that measures the days required to exhaust the medication if taken at the maximum dose prescribed. Patients were classified into 3 mutually exclusive groups: 1 to 30 days, 31 to 90 days, and longer than 90 days' continuous supply. Opioid use of longer than 90 days was chosen as the upper threshold because too few patients were available in private sector samples to model subgroups beyond 180 days. Duration of use was computed until end of follow-up or the start of a longer than 30-day gap.

A morphine equivalent dose was calculated using standard equianalgesic conversion tables that provide the amount of morphine equivalent to the opioid in a given medication (eg, oxycodone). Daily dose was computed from days' supply and total dispensed, assuming patients took the maximum dose prescribed per day. The MED of opioid on the last day before the end of the follow-up period or the last day before a longer than 30-day gap was used to assign patients to 1 of 3 mutually exclusive groups: 1 to $50 \mathrm{mg} / \mathrm{d}, 51$ to $100 \mathrm{mg} / \mathrm{d}$, and greater than $100 \mathrm{mg} / \mathrm{d}$ MED.

\section{Outcome}

New-onset depression was defined by 2 or more outpatient diagnoses (ICD-9-CM codes: 296.2, 296.3 and 311) within the same 12 -month period or 1 or more inpatient diagnoses for depression. This diagnostic 
algorithm has a $99 \%$ positive predictive value for a chart-reviewed diagnosis, ${ }^{24}$ and an $88 \%$ positive predictive value and a $71 \%$ negative predictive value compared with self-reported lifetime of depression. ${ }^{25}$

\section{Covariates}

Except for pain scores and marital status, available only in VHA data, variables were available and measured the same way in each patient cohort. Demographics included age, sex, race, marital status, and insurance. Insurance was defined as federal coverage only (VHA and Medicare) vs other sources. ICD-9-CM codes were used to define posttraumatic stress disorder, any other anxiety disorder (a composite of panic disorder, generalized anxiety disorder, social phobia, obsessive compulsive disorder, or anxiety disorder not otherwise specified), alcohol abuse/dependence and illicit drug abuse/dependence (which includes opioid abuse/ dependence), and nicotine dependence or history of smoking. Comorbid health conditions included type 2 diabetes mellitus, hypertension, cerebrovascular disease, low testosterone levels, sleep apnea, obesity defined by body mass index or ICD-9-CM code, and cardiovascular disease (a composite of hyperlipidemia, ischemic heart disease, disease of pulmonary circulation, other heart disease, hypertensive heart disease, or myocardial infarction).

Painful conditions comprised 5 categories: arthritis, back pain, headaches, musculoskeletal pain, and neuropathic pain, using previously reported ICD-9-CM codes for more than 900 conditions for which an opioid may be prescribed. ${ }^{14,26}$ In VHA data we adjusted analyses for maximum pain scores reported at any time before the end of the follow-up period. The pain score is collected by a stand-alone clinical instrument used in primary care visits. The score is on a 10-point scale, with higher scores indicating worse pain.

To adjust for detection bias, we created a health care utilization variable defined by quartiles of the average number of clinic visits per month.

\section{Propensity Scores and Data Weighting}

Bias by indication may confound the association between duration or dose of opioid analgesic use and new-onset depression. To observe the direct contribution of opioid use to new-onset depression, potential confounders were balanced across levels of duration of opioid use and levels of MED using propensity scores. The propensity score is a conditional probability that a patient will receive a treatment. Covariates described above, including MED, were in the duration model. These same variables, plus opioid use duration, were included in the dose model. After obtaining the propensity scores, we applied inverse probability of treat- ment weighting using standard approaches. ${ }^{27-29}$ Weighting resulted in 2 pseudopopulations within each source of patient data, 1 for duration and 1 for dose. In the weighted data, survival models are not confounded by factors that predict exposure, as detailed elsewhere. ${ }^{27-30}$

\section{Analysis}

Before weighting data, we computed bivariate analyses including analysis of variance and $t$ tests for continuous variables and $\chi^{2}$ tests for categorical variables. Bivariate analyses were recomputed after weighting to determine that variables balanced across levels of opiate use duration and MED. Observation time was defined as month of depression diagnosis since start of the follow-up period or right-censoring time. Right-censoring time is month of last known visit relative to the start of the follow-up period. Hazard ratios for time to new-onset depression were estimated using Cox proportional hazards models in which opioid use duration and MED were time-dependent variables. Fully adjusted Cox models included additional, time-dependent control variables for painful conditions and, in the VHA cohort, pain scores to account for change in pain after opioid initiation. The PHREG procedure in SAS 9.4 (SAS Institute), with $\alpha$ set at .05, was used for the Cox regression models. Evaluation of hazard trends over time confirmed that proportional hazard assumptions were met for both duration $(P=.33, P=.29, P=.08$ in VHA, BSWH, HFHS, respectively) and dose $(P=.62, P=.36, P=.13$ in VHA, BSWH, and HFHS, respectively). Two-tailed tests were conducted to allow for both risk factors and protective effects. This project was approved by the institutional review boards of participating institutions.

\section{RESULTS}

After excluding patients with missing data on any covariate, there were 70,997 VHA, 13,777 BSWH, and 22,981 HFHS patients who were opioid-naive and free of depression at the start of follow-up (Figures 1, 2 and 3). VHA patients were on average older, predominately male, and had a higher percentage of longer than 90 days of opioid use compared with private sector patients. The distributions of MED and other patient characteristics by health system are shown in Table 1.

Among VHA patients, $11.6 \%$ of 1 - to 30 -day users, $13.6 \%$ of 31 - to 90 -day users, and $14.4 \%$ of longer than 90-day users had new-onset depression. Among BSWH patients, cases of new-onset depression increased from $8.4 \%$ of 1 - to 30 -day users to $10.6 \%$ of 31 - to 90 -day users to $19 \%$ among longer than 90 -day users. In HFHS patients, cases of new-onset depression increased from $10.7 \%$ in 1 - to 30 -day users to $14.8 \%$ in 31 - to 90 -day users to $19.3 \%$ in longer than 90 -day users. 
Figure 1. Eligibility criteria for Veterans Hospital Administration patient population.

500,000 Random sample, aged

18-80 years on January 1, 2000

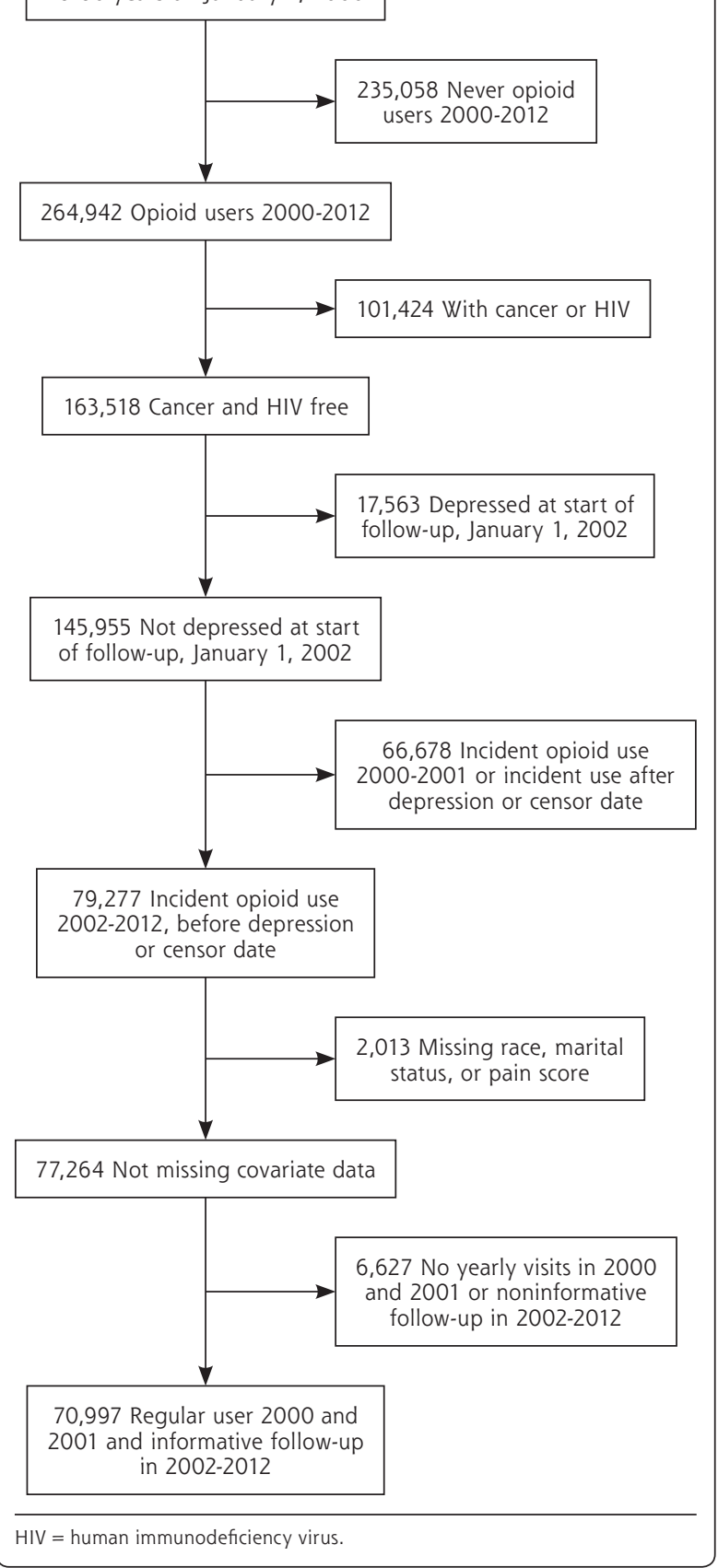

New-onset depression was significantly associated with MED in VHA patients $(P<.0001)$ but not in BSWH and HFHS patients. In VHA patients new-onset depression increased from $11.9 \%$ among those using 1 to $50 \mathrm{mg} / \mathrm{d}$ of MED to $14.2 \%$ in those using 51 to 100 $\mathrm{mg} / \mathrm{d}$ of MED to $20.1 \%$ in those using greater than 100 $\mathrm{mg} / \mathrm{d}$ of MED. In BSWH patients new-onset depres-
Figure 2. Eligibility criteria for Baylor Scott $\mathcal{E}$ White patient population.

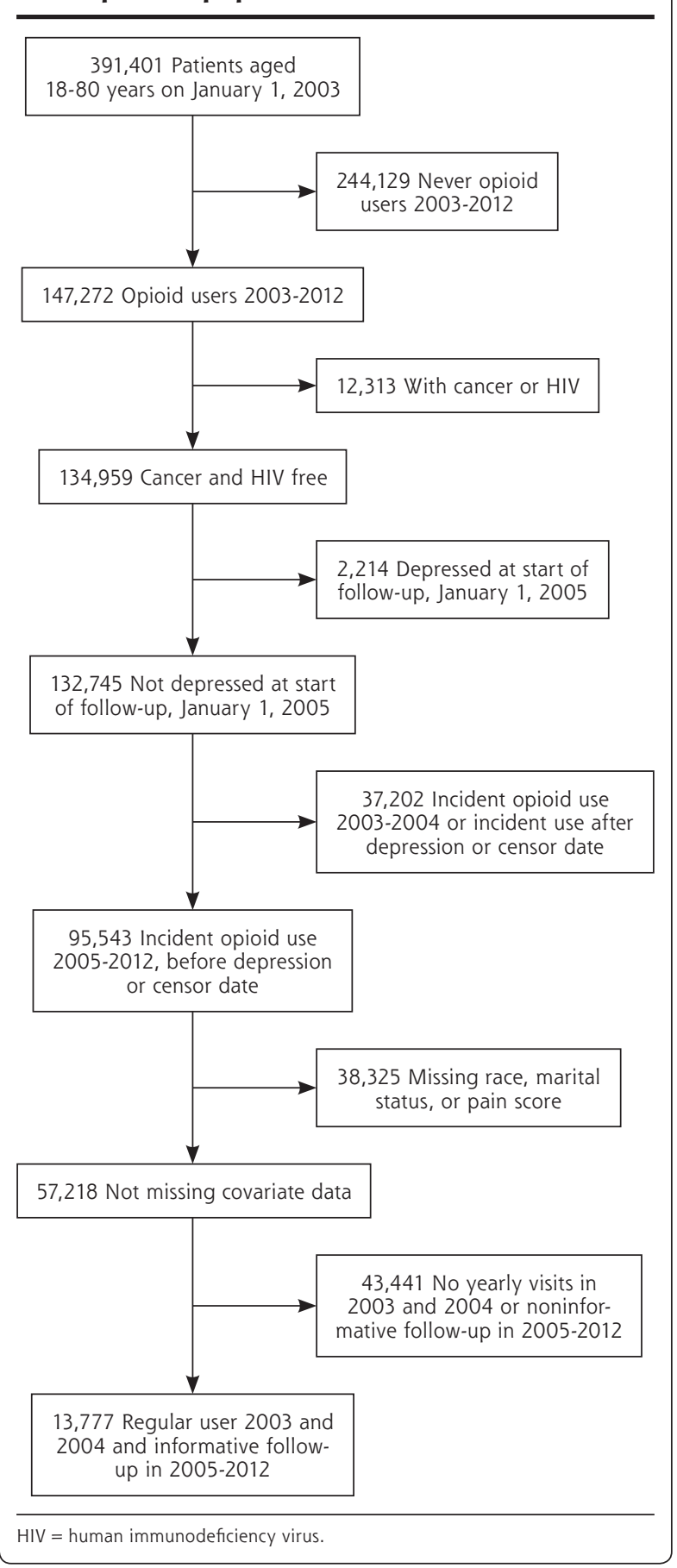

sion occurred in $8.7 \%$ of those using 1 to $50 \mathrm{mg} / \mathrm{d}$ of MED, in $7.7 \%$ of those using 51 to $100 \mathrm{mg} / \mathrm{d} \mathrm{MED,} \mathrm{and}$ in $9.6 \%$ of those using greater than $100 \mathrm{mg} / \mathrm{d}$ MED. In HFHS patients new-onset depression occurred in 11.3\% of those using 1 to $50 \mathrm{mg} / \mathrm{d}$ of MED, in $10.8 \%$ of those using 51 to $100 \mathrm{mg} / \mathrm{d}$ of MED, and in $12.4 \%$ of those using greater than $100 \mathrm{mg} / \mathrm{d}$ of MED. 


\section{Figure 3. Eligibility criteria Henry Ford Health System patient population.}

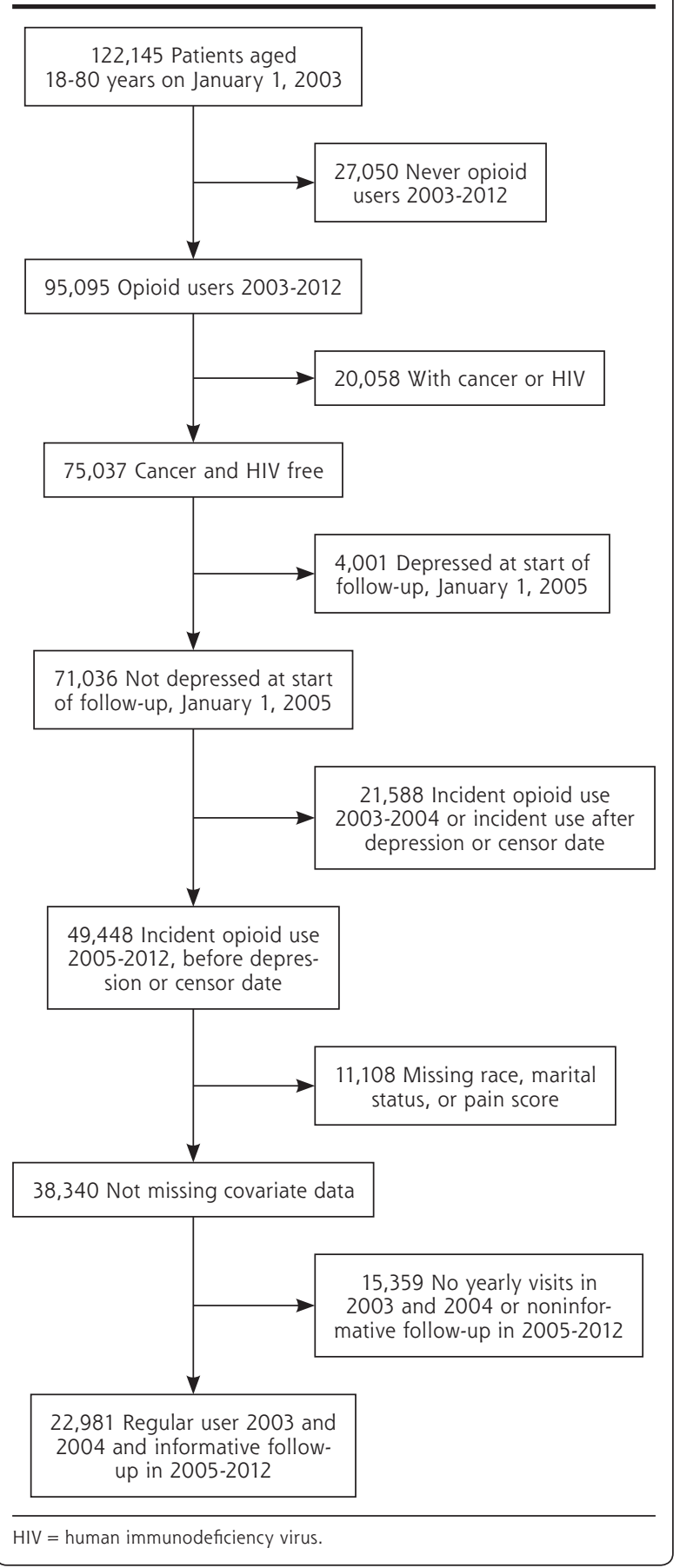

The bivariate relationships between opiate analgesic users, covariates, and new onset of depression are available in Supplemental Appendix 1, Table 1, available at http://www.annfammed.org/content/14/1/54/ suppl/DC1. In each patient sample, opioid use duration and covariates were significantly associated with a new onset of depression. The bivariate associations between new-onset depression and covariates and duration of opioid use are shown in Supplemental Appendix 1, Table 2, and the bivariate associations of these variables by MED are available in Supplemental Appendix 1, Table 3. Propensity scores models and inverse probability of treatment weighting were successful in removing significant associations between covariates and opioid use duration and dose. Balanced covariate distributions are shown by opioid use duration (Supplemental Appendix 1, Table 4) and dose (Supplemental Appendix 1, Table 5). The prevalence of back pain across opioid use duration in the BSWH patient sample did not balance, however, this variable is included in multivariate survival models.

As shown in Table 2, before weighting data (model 1), VHA patients who were 31- to 90-day users were significantly more likely to develop new-onset depression (hazard ratio $[\mathrm{HR}]=1.23,95 \% \mathrm{CI}, 1.16-1.31$ ) compared with 1- to 30-day opioid users. Similar results were found in BSWH and HFHS patients. Compared with 1- to 30-day opioid use, longer than 90 days of opioid use was significantly associated with new-onset depression in each patient sample.

In all 3 patient samples, after weighting data and adjusting further for potential persistent painful conditions (see model 3), 31 to 90 days of opioid use, compared with 1 to 30 days of opioid use, was significantly associated with new-onset depression (HR range $=1.18-1.33$ ), and opioid use longer than 90 days, compared with 1 to 30 days, was significantly associated with new-onset depression (HR range $=1.35$ 2.05). Hazard ratios obtained for risk from 31 to 90 days and longer than 90 days of opioid use were significantly different from each other in VHA and HFHS patient samples.

As displayed in Table 3, before balancing variables in model 1 and without covariate adjustment, higher MED was associated with a new onset of depression. There were no significant associations between MED and new-onset depression in BSWH and HFHS patient samples before data weighting (model 1). After weighting data and additional adjustment for pain in model 3, and also for pain scores in VHA data, MED was not significantly associated with new-onset depression in VHA, BSWH, and HFHS patients.

\section{DISCUSSION}

In 3 separate diverse patient populations, longer duration of opioid analgesic use was associated with episodes of new-onset depression after controlling for pain conditions and daily MED. Hazard ratios increased from 1.18 (VHA) to 1.33 (HFHS) for 31- to 90- day opioid use to a range of 1.35 (VHA) to 2.05 
Table 1. Distribution of Opioid Exposure and Covariates by Health Care Organization

\begin{tabular}{|c|c|c|c|}
\hline Variable & $\begin{array}{c}\text { VHA } \\
(n=70,997)\end{array}$ & $\begin{array}{c}\text { BSWH } \\
(n=13,777)\end{array}$ & $\begin{array}{c}\text { HFHS } \\
(n=22,981)\end{array}$ \\
\hline Age, mean (SD), y & $55.4(13.0)$ & $44.6(15.1)$ & $47.7(14.4)$ \\
\hline Sex, male, No. (\%) & $66,697(93.9)$ & $5,163(37.5)$ & 9,167 (39.9) \\
\hline Race, white, No. (\%) & $53,790(75.8)$ & $9,542(69.3)$ & $10,696(46.5)$ \\
\hline \multicolumn{4}{|l|}{ Insurance } \\
\hline VHA only, No. (\%) & $46,196(65.1)$ & $\ldots$ & $\ldots$ \\
\hline Medicare, No. (\%) & $\ldots$ & $1,846(13.4)$ & $170(0.7)$ \\
\hline Married, No. (\%) & $39,076(55.0)$ & $\ldots$ & $\ldots$ \\
\hline \multicolumn{4}{|l|}{ Opioid use duration } \\
\hline 1 to $30 \mathrm{~d}$, No. $(\%)$ & $55,306(77.9)$ & $12,817(93.0)$ & $20,487(89.1)$ \\
\hline 31 to 90 d, No. (\%) & $8,640(12.2)$ & $765(5.6)$ & $1,685(7.3)$ \\
\hline$>90$ d, No. (\%) & $7,051(9.9)$ & $195(1.4)$ & $809(3.5)$ \\
\hline \multicolumn{4}{|l|}{ Last MED dose $\mathrm{e}^{\mathrm{a}}$} \\
\hline 1 to $50 \mathrm{mg} / \mathrm{d}$, No. (\%) & $66,601(93.8)$ & $12,893(93.6)$ & $20,006(87.1)$ \\
\hline 51 to $100 \mathrm{mg} / \mathrm{d}$, No. (\%) & $3,613(5.1)$ & $706(5.1)$ & $2,628(11.4)$ \\
\hline >100 mg/d, No. (\%) & $783(1.1)$ & $178(1.3)$ & $347(1.5)$ \\
\hline \multicolumn{4}{|l|}{ Psychiatric comorbidity } \\
\hline $\begin{array}{l}\text { Posttraumatic stress disorder, } \\
\text { No. (\%) }\end{array}$ & $10,357(14.6)$ & $35(0.3)$ & $123(0.5)$ \\
\hline Other anxiety, No. $(\%)^{c}$ & $8,383(11.8)$ & $771(5.6)$ & $2,057(9.0)$ \\
\hline $\begin{array}{l}\text { Nicotine dependence/history of } \\
\text { smoking, No. (\%) }\end{array}$ & $30,175(42.5)$ & $1,070(7.8)$ & $5,274(22.9)$ \\
\hline $\begin{array}{l}\text { Alcohol abuse/dependence, } \\
\text { No. (\%) }\end{array}$ & $14,313(20.2)$ & $234(1.7)$ & $1,010(4.4)$ \\
\hline $\begin{array}{l}\text { Any illicit drug abuse/dependence, } \\
\text { No. (\%) }\end{array}$ & $8,727(12.3)$ & $101(0.7)$ & $625(2.7)$ \\
\hline \multicolumn{4}{|l|}{ Metabolic/cardiovascular comorbidity ${ }^{b}$} \\
\hline Diabetes type 2, No. (\%) & $29,946(42.2)$ & $2,732(19.8)$ & $7,101(30.9)$ \\
\hline Hypertension, No. (\%) & $58,616(82.6)$ & $6,845(49.7)$ & $15,857(69.0)$ \\
\hline Cardiovascular disease, No. (\%) & $61,380(86.5)$ & $8,161(59.2)$ & $17,444(75.9)$ \\
\hline Cerebrovascular disease, No. (\%) & $14,938(21.0)$ & $1,370(9.9)$ & $3,560(15.5)$ \\
\hline Obesity diagnosis, No. (\%) & $27,621(38.9)$ & $2,640(19.2)$ & $6,522(28.4)$ \\
\hline \multicolumn{4}{|l|}{ Other comorbidity ${ }^{b}$} \\
\hline Low testosterone, No. (\%) & $2,171(3.1)$ & $219(1.6)$ & $313(1.4)$ \\
\hline Sleep apnea, No. (\%) & $7,563(10.6)$ & $1,196(8.7)$ & $1,583(6.9)$ \\
\hline \multicolumn{4}{|l|}{ Painful condition ${ }^{b}$} \\
\hline Arthritis, No. (\%) & $58,504(82.4)$ & $8,539(62.0)$ & $18,381(80.0)$ \\
\hline Back pain, No. (\%) & $46,592(65.6)$ & $7,323(53.2)$ & $15,915(69.3)$ \\
\hline Headache, No. (\%) & $14,389(20.3)$ & $3,631(26.4)$ & $8391(36.5)$ \\
\hline Musculoskeletal pain, No. (\%) & $44,817(63.1)$ & $9,149(66.4)$ & $19,273(83.9)$ \\
\hline Neuropathic pain, No. (\%) & $22,995(32.4)$ & $2,391(17.4)$ & $5,212(22.7)$ \\
\hline Maximum pain score, mean (SD) & $8.4(2.2)$ & $\ldots$ & $\ldots$ \\
\hline \multicolumn{4}{|l|}{ Health care utilization } \\
\hline$\leq 25$ th percentile, No. (\%) & $6,937(9.8)$ & $3,134(22.8)$ & $4,379(19.1)$ \\
\hline 26 to 50th percentile, No. (\%) & $19,928(28.1)$ & $4,394(31.9)$ & $\ldots$ \\
\hline 51 to 75 th percentile, No. (\%) & $24,540(34.6)$ & $2,758(20.0)$ & $13,620(59.3)$ \\
\hline >75th percentile, No. (\%) & $19,592(27.6)$ & $3,491(25.3)$ & $4,982(21.7)$ \\
\hline
\end{tabular}

BSWH = Baylor Scott $\&$ White Health; GAD = generalized anxiety disorder; HFHS = Henry Ford Health System; $\mathrm{MED}=$ morphine equivalent dose; $\mathrm{VHA}=$ Veterans Health Administration.

a Opioid MED at end of follow-up period defined by new-onset depression, end, or incident opioid prescription, or last available observation.

${ }^{\mathrm{b}}$ Comorbidities occurring before new-onset depression.

' Other anxiety disorders include panic disorder, obsessive-compulsive disorder, social phobia, generalized anxiety disorder, anxiety not otherwise specified.

${ }^{d}$ Cardiovascular diseases include hyperlipidemia, ischemic heart disease, diseases of pulmonary circulation, other heart disease, hypertensive heart disease, myocardial infarction.
(HFHS) for longer than 90 days or opioid use, these point estimates are significantly different from each other in VHA and HFHS. We observed that higher MED (greater than $100 \mathrm{mg} / \mathrm{d}$ ) compared with lower daily MED $(1$ to $50 \mathrm{mg} / \mathrm{d}$ ) was not associated with new-onset depression in models controlling for pain and opioid use duration. This finding is not consistent with our previous study, which found that increased MED is associated with greater probability of newonset depression. It is possible that increasing the MED was a proxy for duration in our previous report. ${ }^{15}$

Research on the efficacy of opioids in depression treatment, limited by small samples, short follow-up time, and lack of control groups, does not support opioids as effective long-term treatments for depression. ${ }^{31}$ This evidence, combined with the finding from the present study, supports the conclusion that opioids may cause short-term improvement in mood, but longterm use is associated with risk of new-onset depression.

\section{Limitations}

Duration of opioid use did not account for intermittent opioid administration by patients and frequency of dose escalation. In preliminary analysis of VHA patient data, we found no evidence of a dose-by-duration effect and no evidence that risk increased with longer use at higher doses. The report of pain is generated in the clinical setting. Thus, self-report bias is a possible limitation, because patients seeking opioids and those with poor mood may report more pain. We did not have statistical power to model use of longer than 180 days in private sector data. We speculate 
that risk would continue to increase with longer durations, because our prior study of VHA data found that longer than 180-day opioid use compared with less than 90-day use was associated with new-onset depression $(\mathrm{HR}=1.51 ; 95 \% \mathrm{CI}, 1.31-1.74) .{ }^{14}$

New-onset depression may have developed during or after opioid use cessation. Post hoc analysis in VHA data indicates $93.2 \%$ of cases of a new onset of depression occurred after the end of the incident opioid use. Of these patients, $8.7 \%$ had new-onset depression begin within 30 days, $8.3 \%$ within 31 to 180 days, and $82.9 \%$ after 180 days postincident opioid use. The mean lag time between end of incident use and newonset depression was 3.4 years, $(\mathrm{SD}=2.5$ years). This lag time may be an overestimate, because symptoms of depression often begin well before patients seek treatment and receive a diagnosis.

The current body of research contributes some evidence toward causality ${ }^{32}$ in that there is consistency of findings for duration of use across samples with substantial variation in demographic and disease profiles, the association is strong, and the temporal order is established. A dose-response relationship, however, does not exist for MED and new-onset depression, and residual confounding, especially in the case of maximum dose, may be present. A contribution of dose to new-onset depression should not be ruled out. Prospective data collection to obtain information on

Table 2. Association Between Duration of Incident Opioid Use and New-Onset Depression, Unweighted and Weighted by Inverse Probability Duration Exposure

\begin{tabular}{|c|c|c|c|c|c|c|}
\hline \multirow[b]{2}{*}{ Variable } & \multicolumn{3}{|c|}{ VHA Patients } & \multicolumn{3}{|c|}{ BSWH Patients } \\
\hline & $\begin{array}{c}\text { Model 1a } \\
\text { HR }(95 \% \mathrm{Cl})\end{array}$ & $\begin{array}{c}\text { Model } 2^{b} \\
\text { HR }(95 \% \mathrm{Cl})\end{array}$ & $\begin{array}{c}\text { Model 3c } \\
\text { HR }(95 \% \mathrm{Cl})\end{array}$ & $\begin{array}{c}\text { Model 1a } \\
\text { HR }(95 \% \mathrm{Cl})\end{array}$ & $\begin{array}{c}\text { Model } 2^{b} \\
\text { HR }(95 \% \mathrm{Cl})\end{array}$ & $\begin{array}{c}\text { Model 3c } \\
\text { HR }(95 \% \mathrm{Cl})\end{array}$ \\
\hline \multicolumn{7}{|l|}{ Opioid duration } \\
\hline 1 to $30 \mathrm{~d}$ & 1.00 [Reference] & 1.00 [Reference] & 1.00 [Reference] & 1.00 [Reference] & 1.00 [Reference] & 1.00 [Reference] \\
\hline 31 to $90 \mathrm{~d}$ & $1.23(1.16-1.31)$ & $1.20(1.13-1.28)$ & $1.18(1.10-1.25)$ & $1.22(0.97-1.52)$ & $1.31(1.05-1.65)$ & $1.29(1.03-1.62)$ \\
\hline$>90 \mathrm{~d}$ & $1.31(1.22-1.40)$ & $1.39(1.30-1.48)$ & $1.35(1.26-1.44)$ & $2.26(1.63-3.14)$ & $2.04(1.38-3.02)$ & $1.88(1.27-2.78)$ \\
\hline Arthritis & $\ldots$ & $\ldots$ & $1.18(1.12-1.25)$ & $\ldots$ & $\ldots$ & $1.35(1.17-1.56)$ \\
\hline Back pain & $\ldots$ & $\ldots$ & $1.48(1.41-1.56)$ & $\ldots$ & $\ldots$ & $1.43(1.27-1.61)$ \\
\hline Headache & $\ldots$ & $\ldots$ & $1.59(1.52-1.67)$ & $\ldots$ & $\ldots$ & $1.95(1.73-2.20)$ \\
\hline Musculoskeletal pain & $\ldots$ & $\ldots$ & $1.32(1.26-1.39)$ & $\ldots$ & $\ldots$ & $0.76(0.66-0.88)$ \\
\hline Neuropathy & $\ldots$ & $\ldots$ & $1.12(1.07-1.17)$ & $\ldots$ & $\ldots$ & $1.41(1.21-1.63)$ \\
\hline Pain score & $\ldots$ & $\ldots$ & $1.24(1.22-1.26)$ & $\ldots$ & $\ldots$ & $\ldots$ \\
\hline
\end{tabular}

BSWH = Baylor Scott $\&$ White Health; HFHS = Henry Ford Health System; HR = hazard ratio; VHA = Veterans Health Administration.

a Unweighted data.

b Weighted data.

CWeighted data plus pain.

Table 3. Association Between Last Daily Morphine Equivalent Dose of Incident Opioid Use and New-Onset Depression, Unweighted and Weighted By Inverse Probability Dose Exposure

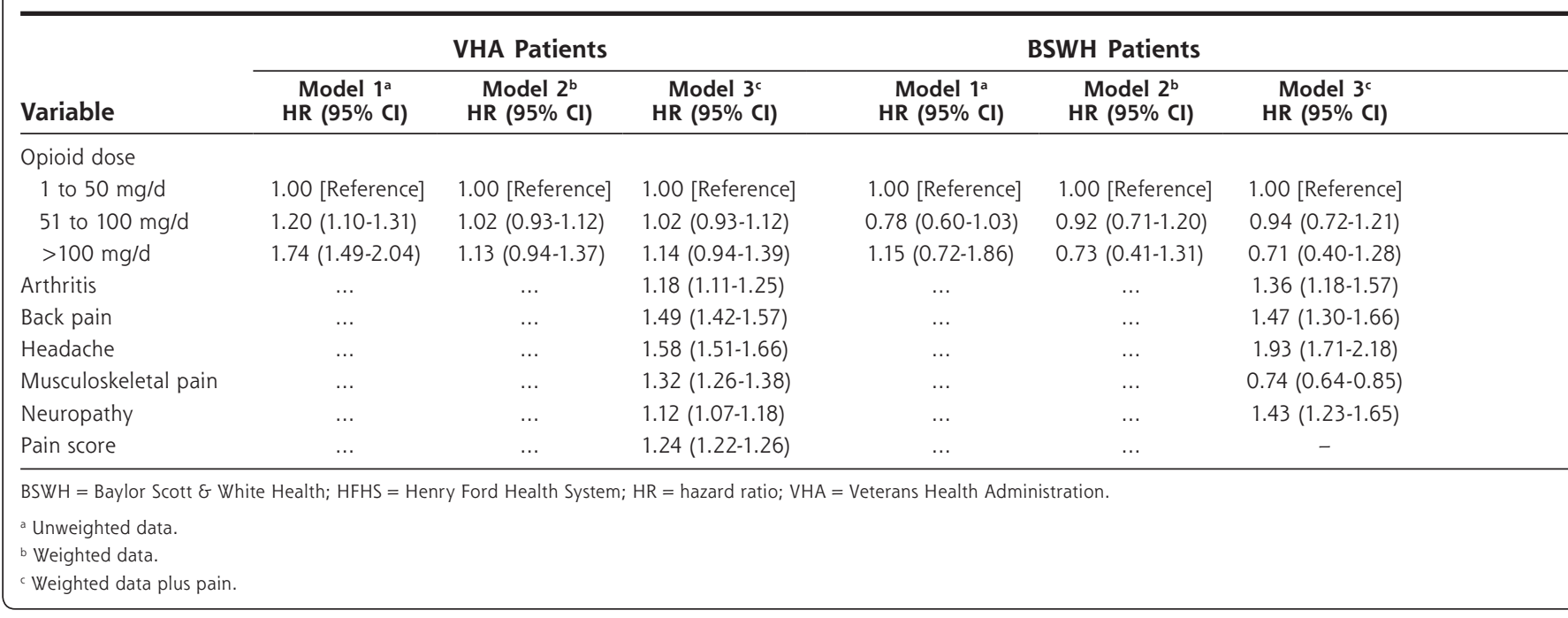


impaired functioning, opioid misuse, and family dysfunction is warranted.

There are several potential mechanisms for our findings. We speculate that long-term opioid analgesic use could lead to hyperalgesia, ${ }^{33}$ which in turn leads to a new onset of depression. Chronic opioid use may cause changes in neuroanatomy. Opioid analgesic use lasting 9 years vs less than 1 year in humans correlated with changes in functional connectivity in the nucleus accumbens and amygdala, regions associated with mood regulation, impulse control, reward, and motivation. ${ }^{34}$ Patients using an average of $78 \mathrm{mg}$ of morphine per day had reduced gray matter in amygdala after 30 days of use, with changes persisting for at least 4.7

HFHS Patients

Model $1^{\mathrm{a}} \quad$ Model $2^{\mathrm{b}} \quad$ Model $3^{\mathrm{c}}$
HR $(95 \% \mathrm{Cl})$ $\operatorname{HR}(95 \% \mathrm{Cl})$ HR $(95 \% \mathrm{Cl})$

1.00 [Reference]

1.39 (1.22-1.59)

1.00 [Reference]

1.00 [Reference]

$1.90(1.62-2.24)$

1.33 (1.16-1.52)

1.33 (1.16-1.52)

2.19 (1.87-2.56)

$2.05(1.75-2.40)$

$1.36(1.22-1.51)$

1.43 (1.31-1.57)

1.52 (1.41-1.65)

$1.24(1.11-1.38)$

$1.32(1.20-1.44)$

$\ldots$ months after opioid cessation. ${ }^{35}$ These studies support the hypothesis that opioid exposure leads to neuroanatomical disturbance in brain regions associated with reward and pleasure, which could be the mechanism underlying new-onset depression. Consequences of chronic opioid analgesic use, such as low testosterone and opioid misuse, could also be in the causal pathway to new-onset depression.

Using the hazard ratio found in the VHA patient population, the number of patients exposed to longer than 90 days of opioid analgesic use that resulted in 1 subsequent case of depression during our observation period is 12 . Depression is a substantial public health problem given the magnitude of opioid exposure in the United States. The current results highlight additional concerns for primary care physicians of whom many report frustration and substantial burden in provision of optimal pain management. ${ }^{20}$

Patients should be informed of this association and be monitored for depression. Clinicians should consider the pain-independent contribution of opioid use when depressed mood develops. Further research is warranted to identify which patients are most vulnerable to opioid-related depression.

To read or post commentaries in response to this article, see it online at http://www.annfammed.org/content/14/1/54.

Key words: analgesics, opioid; depression; cohort; epidemiology

Submitted June 29, 2015; submitted, revised, September 17, 2015; accepted October 19, 2015.

Funding support: This study was supported by the National Institute of Mental Health, Prescription Opioid Analgesics and Risk of Depression, R21MH101389. This work also received support from the Veterans Health Administration.

Disclaimer: Funding sources had no role in study design; in the collection, analysis and interpretation of data; in the writing of the report; or in the decision to submit the paper for publication. The views are the authors and do not necessarily reflect the views of the Department of Veterans Affairs.

Previous publication: Portions of this study were presented to the North American Primary Care Research Group Scientific Meeting, Cancun, Mexico, October, 2015.

Acknowledgment: Yong Hu provided HFHS data analysis.

Supplementary materials: Available at http://www.AnnFamMed. org/content/14/1/54/suppl/DC1.

\section{References}

1. Fishbain DA, Cutler R, Rosomoff HL, Rosomoff RS. Chronic painassociated depression: antecedent or consequence of chronic pain? A review. Clin J Pain. 1997;13(2):116-137.

2. Kroenke K, Wu J, Bair MJ, Krebs EE, Damush TM, Tu W. Reciprocal relationship between pain and depression: a 12-month longitudinal analysis in primary care. J Pain. 2011;12(9):964-973. 
3. Sullivan MD, Edlund MJ, Zhang L, Unützer J, Wells KB. Association between mental health disorders, problem drug use, and regular prescription opioid use. Arch Intern Med. 2006;166(19):2087-2093.

4. Braden JB, Sullivan MD, Ray GT, et al. Trends in long-term opioid therapy for noncancer pain among persons with a history of depression. Gen Hosp Psychiatry. 2009;31(6):564-570.

5. Psaty BM, Koepsell TD, Lin D, et al. Assessment and control for confounding by indication in observational studies. J Am Geriatr Soc. 1999;47(6):749-754.

6. Merrill JO, Von Korff M, Banta-Green CJ, et al. Prescribed opioid difficulties, depression and opioid dose among chronic opioid therapy patients. Gen Hosp Psychiatry. 2012;34(6):581-587.

7. Grattan A, Sullivan MD, Saunders KW, Campbell Cl, Von Korff MR. Depression and prescription opioid misuse among chronic opioid therapy recipients with no history of substance abuse. Ann Fam Med. 2012;10(4):304-311.

8. Rassen JA, Glynn RJ, Brookhart MA, Schneeweiss S. Covariate selection in high-dimensional propensity score analyses of treatment effects in small samples. Am J Epidemiol. 2011;173(12):1404-1413.

9. Howe $C Q$, Sullivan MD. The missing ' $P$ ' in pain management: how the current opioid epidemic highlights the need for psychiatric services in chronic pain care. Gen Hosp Psychiatry. 2014;36(1):99-104.

10. Volkow ND, McLellan TA, Cotto JH, Karithanom M, Weiss SR. Characteristics of opioid prescriptions in 2009. JAMA. 2011;305(13): 1299-1301.

11. Volkow ND. Drug abuse and mental illness: progress in understanding comorbidity. Am J Psychiatry. 2001;158(8):1181-1183.

12. Franklin $G$, Sabel J, Jones $C M$, et al. A comprehensive approach to address the prescription opioid epidemic in Washington State: milestones and lessons learned. Am J Public Health. 2015;105(3):463-469.

13. Franklin GM; American Academy of Neurology. Opioids for chronic noncancer pain: a position paper of the American Academy of Neurology. Neurology. 2014;83(14):1277-1284.

14. Scherrer JF, Svrakic DM, Freedland KE, et al. Prescription opioid analgesics increase the risk of depression. J Gen Intern Med. 2014; 29(3):491-499.

15. Scherrer JF, Salas J, Lustman PJ, Burge S, Schneider FD; Residency Research Network of Texas (RRNeT) Investigators. Change in opioid dose and change in depression in a longitudinal primary care patient cohort. Pain. 2015;156(2):348-355.

16. Wasan AD, Davar G, Jamison R. The association between negative affect and opioid analgesia in patients with discogenic low back pain. Pain. 2005;117(3):450-461.

17. Grattan A, Sullivan MD, Saunders KW, Campbell Cl, Von Korff MR. Depression and prescription opioid misuse among chronic opioid therapy recipients with no history of substance abuse. Ann Fam Med. 2012;10(4):304-311.

18. Edlund MJ, Martin BC, Fan MY, Devries A, Braden JB, Sullivan MD. Risks for opioid abuse and dependence among recipients of chronic opioid therapy: results from the TROUP study. Drug Alcohol Depend. 2010;112(1-2):90-98.

19. Sullivan MD, Edlund MJ, Fan MY, Devries A, Brennan Braden J, Martin BC. Risks for possible and probable opioid misuse among recipients of chronic opioid therapy in commercial and medicaid insurance plans: The TROUP Study. Pain. 2010;150(2):332-339.
20. Leverence RR, Williams RL, Potter M, et al; PRIME Net Clinicians. Chronic non-cancer pain: a siren for primary care-a report from the PRImary Care MultiEthnic Network (PRIME Net). J Am Board Fam Med. 2011;24(5):551-561.

21. Scherrer JF, Chrusciel T, Zeringue A, et al. Anxiety disorders increase risk for incident myocardial infarction in depressed and nondepressed Veterans Administration patients. Am Heart J. 2010; 159(5):772-779.

22. Ross TR, Ng D, Brown JS, Pardee R. The HMO research network virtual data warehouse: a public data model to support collaboration. eGEMS. 2014;2(1):1049.

23. Scherrer JF, Garfield LD, Chrusciel T, et al. Increased risk of myocardial infarction in depressed patients with type 2 diabetes. Diabetes Care. 2011;34(8):1729-1734.

24. Solberg LI, Engebretson KI, Sperl-Hillen JM, Hroscikoski MC, O'Connor PJ. Are claims data accurate enough to identify patients for performance measures or quality improvement? The case of diabetes, heart disease, and depression. Am J Med Qual. 2006;21(4): 238-245.

25. Frayne SM, Miller DR, Sharkansky EJ, et al. Using administrative data to identify mental illness: what approach is best? Am J Med Qual. 2010;25(1):42-50.

26. Seal KH, Shi Y, Cohen G, et al. Association of mental health disorders with prescription opioids and high-risk opioid use in US veterans of Iraq and Afghanistan. JAMA. 2012;307(9):940-947.

27. Cole SR, Hernán MA. Constructing inverse probability weights for marginal structural models. Am J Epidemiol. 2008;168(6):656-664.

28. Curtis LH, Hammill BG, Eisenstein EL, Kramer JM, Anstrom KJ. Using inverse probability-weighted estimators in comparative effectiveness analyses with observational databases. Med Care. 2007; 45(10)(Supl 2):S103-S107.

29. Kilpatrick RDGD, Gilbertson D, Brookhart MA, Polley E, Rothman $\mathrm{KJ}$, Bradbury BD. Exploring large weight deletion and the ability to balance confounders when using inverse probability of treatment weighting in the presence of rare treatment decisions. Pharmacoepidemiol Drug Saf. 2013:22(2):111-121.

30. Rosenbaum PR, Rubin DB. The central role of the propensity score in observational studies for causal effects. Biometrika Trust. 1983;70(1):41-55.

31. Howe CQ, Sullivan MD. The missing ' $P$ ' in pain management: how the current opioid epidemic highlights the need for psychiatric services in chronic pain care. Gen Hosp Psychiatry. 2014;36(1):99-104.

32. Hill $A B$. The environment and disease: association or causation? Proc R Soc Med. 1965;58:295-300.

33. Crofford LJ. Adverse effects of chronic opioid therapy for chronic musculoskeletal pain. Nat Rev Rheumatol. 2010;6(4):191-197.

34. Upadhyay J, Maleki N, Potter J, et al. Alterations in brain structure and functional connectivity in prescription opioid-dependent patients. Brain. 2010;133(Pt 7):2098-2114.

35. Younger JW, Chu LF, D'Arcy NT, Trott KE, Jastrzab LE, Mackey SC. Prescription opioid analgesics rapidly change the human brain. Pain. 2011;152(8):1803-1810. 